Theme: Oxygen Steelmaking

\title{
INSTALLATION OF A 350 T BOF CONVERTER AT ARCELORMITTAL POLAND*
}

\author{
Günther Staudinger ${ }^{1}$ \\ Peter Illecker ${ }^{2}$ \\ Ireneusz Staniewski $i^{3}$ \\ Ryszard Konieczny ${ }^{4}$ \\ Stefan Cichoński
}

\begin{abstract}
Danieli Linz Technology has been honored at 4.1.2013 with the first contract for the exchange of a 350 t BOF converter for ArcelorMittal Poland Dabrowa Gornicza on a turnkey basis. This paper describes the new design features of this converter based on the development of a new Danieli converter suspension system. The issue was to install a new converter (incl. trunnion ring, suspension system and bearings) with maximum volume but keeping most of the existing equipment unchanged. So, the big tilting drives on both sides had to be reused and the existing foundation, pedestals as well as the bearing distance had to be maintained. Further on the welded coreequipment (vessel shell, trunnion ring, pedestals, slag shields, etc.) was manufactured in-house within the pressure vessel division of Danieli Thailand. Due to the huge dimensions of these parts the delivery had to take place in parts which had to be welded together on site under full production conditions of the steel plant. But also the erection had to be applied under this condition. Additionally the main support bearings, parts of the screening (doghouse) as well as an upgrade of the existing relining machine had to be delivered.
\end{abstract}

Keywords: Converter steelmaking; BOF technology; Converter Suspension System; Erection technology.

1 Dr., Executive Vice President, Danieli Linz Technology, Linz, Austria; g.staudinger@austria.danieli.com.

2 Engineer, Executive Manager Engineering, Danieli Linz Technology, Linz, Austria; p.illecker@austria.danieli.com.

3 Dr., Senior Project Manager, ArcelorMittal Poland, Dabrowa Gornicza, Poland; ireneusz.staniewski@arcelormittal.com.

4 Engineer, Support Manager, ArcelorMittal Poland, Dabrowa Gornicza, Poland; ryszard.konieczny@arcelormittal.com.

5 Support Manager, ArcelorMittal Poland, Dabrowa Gornicza, Poland; stefan.cichonski@arcelormittal.com.

${ }^{*}$ Technical contribution to the $45^{\text {th }}$ Steelmaking Seminar, May $25^{\text {th }}-28^{\text {th }}, 2014$, Porto Alegre, RS, Brazil. 


\section{INTRODUCTION}

On 4.1.2013 Danieli was honored with the first contract to revamp a $350 \mathrm{t}$ LD converter for ArcelorMittal Steel Poland Dabrowa Gornicza in Poland.

The converter is one of the biggest world-wide and has a tilting drive on each side of the trunnion ring with 6 electric drives each. These drives will be reused for the new converter equipment. So, the trunnion ring is equipped with to long pins which comes along with large dimensions and a huge length of almost $20 \mathrm{~m}$.

The converter has been designed new to gain maximum inner volume. Due to the new geometry and new weight distribution the tilting torque calculation verifies that additional counter weights have to be arranged on the top cone of the vessel shell in order to keep the maximum tilting torques with the allowable limit of the tilting drives.

The converter suspension system has been developed by Danieli and consists of vertical elements as well as horizontal elements. The design should guarantee an easy installation on site as well as maintenance operation.

The trunnion ring bearings are changed to a state-of-the-art design with adopted converter pedestals.

\section{CONVERTER DESIGN}

Still today the steelmaking converter is one of the most important equipment for producing high quality steel worldwide. From the metallurgical point of view the converter has to provide a certain reaction volume as well as bath depth and surface for the steelmaking process. In order to optimize the steelmaking process the reaction volume should be as much as possible with an ideal value for the specific volume (defined as ratio of inner volume to mass of liquid steel) of approx. 1.0.

To maximize the volume of the converter was an issue as well. Taken into consideration the boundary conditions to keep the actual tilting axes, to maintain a certain clearance to the teeming ladle during tapping and the offgas system as well as the charging and tapping procedure some iterations in the engineering phase have been studied in order to find the right solution.

Finally an increase of the inner volume from $225 \mathrm{~m}^{3}$ to $275 \mathrm{~m}^{3}$ could be achieved. This comes along with an increase from a specific volume of 0.7 to actually of 0.79 . Figura 1 shows the existing vessel and the new vessel.
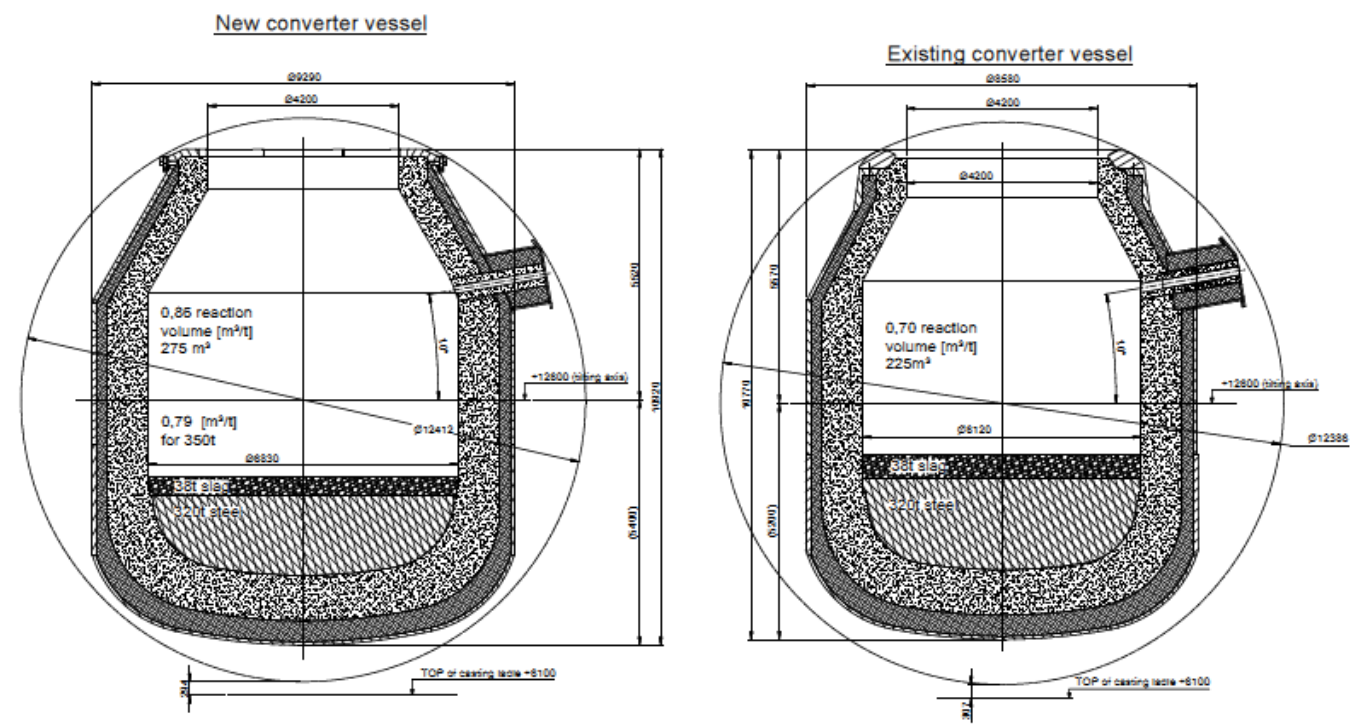

Figure 1. Comparison of new vessel shell to existing vessel shell.

* Technical contribution to the $45^{\text {th }}$ Steelmaking Seminar, May $25^{\text {th }}-28^{\text {th }}, 2014$, Porto Alegre, RS, Brazil. 
This enlargement of the vessel shell could be achieved by a moderate increasing the tilting circle from $12386 \mathrm{~mm}$ to $12412 \mathrm{~mm}$. In parallel a stepped lipring design and a shorter taphole socket was helpful to optimize the shape.

Figure 2 shows the investigation of the charging of hot metal and Figure 3 those for tapping of liquid steel for the new converter design.
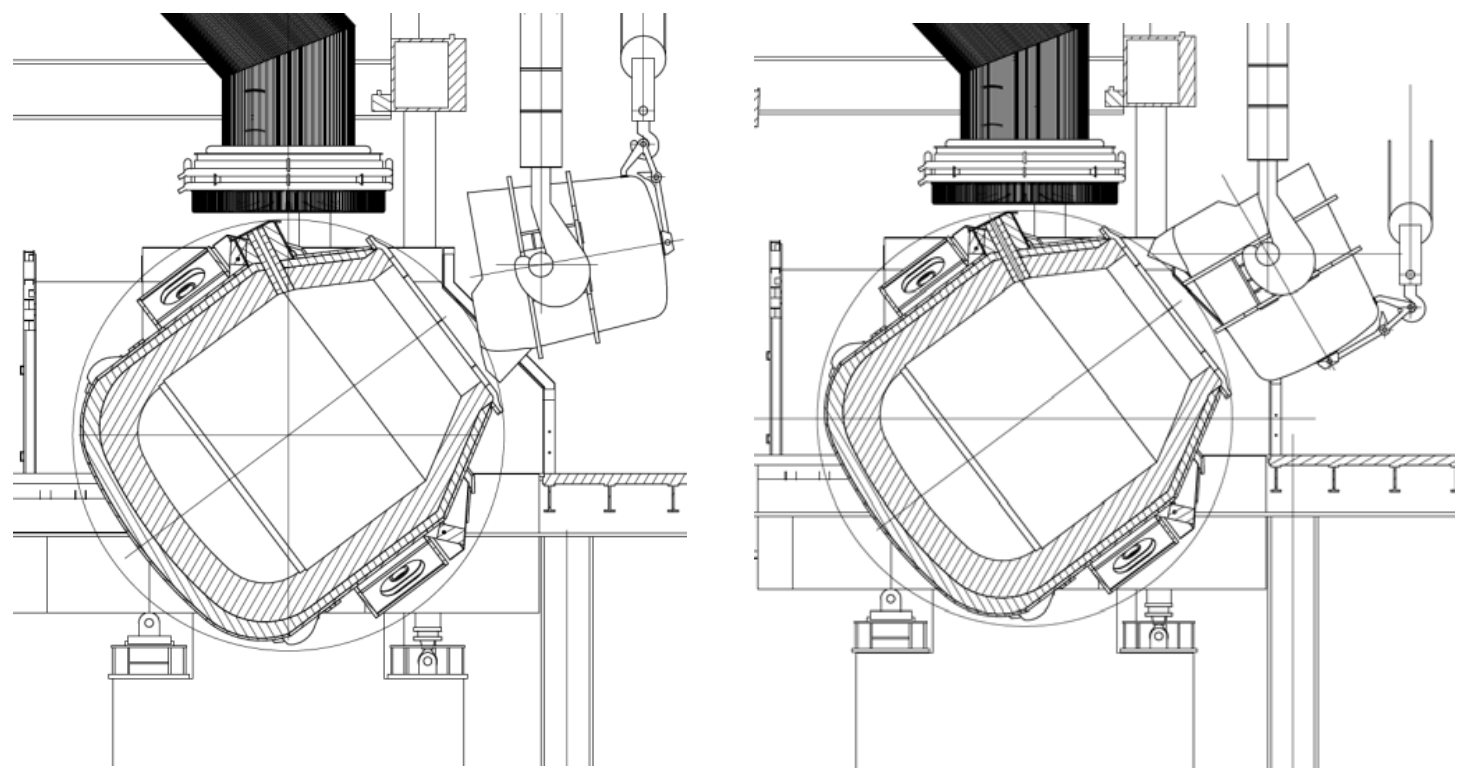

Figure 2. Investigation of charging of hot metal.
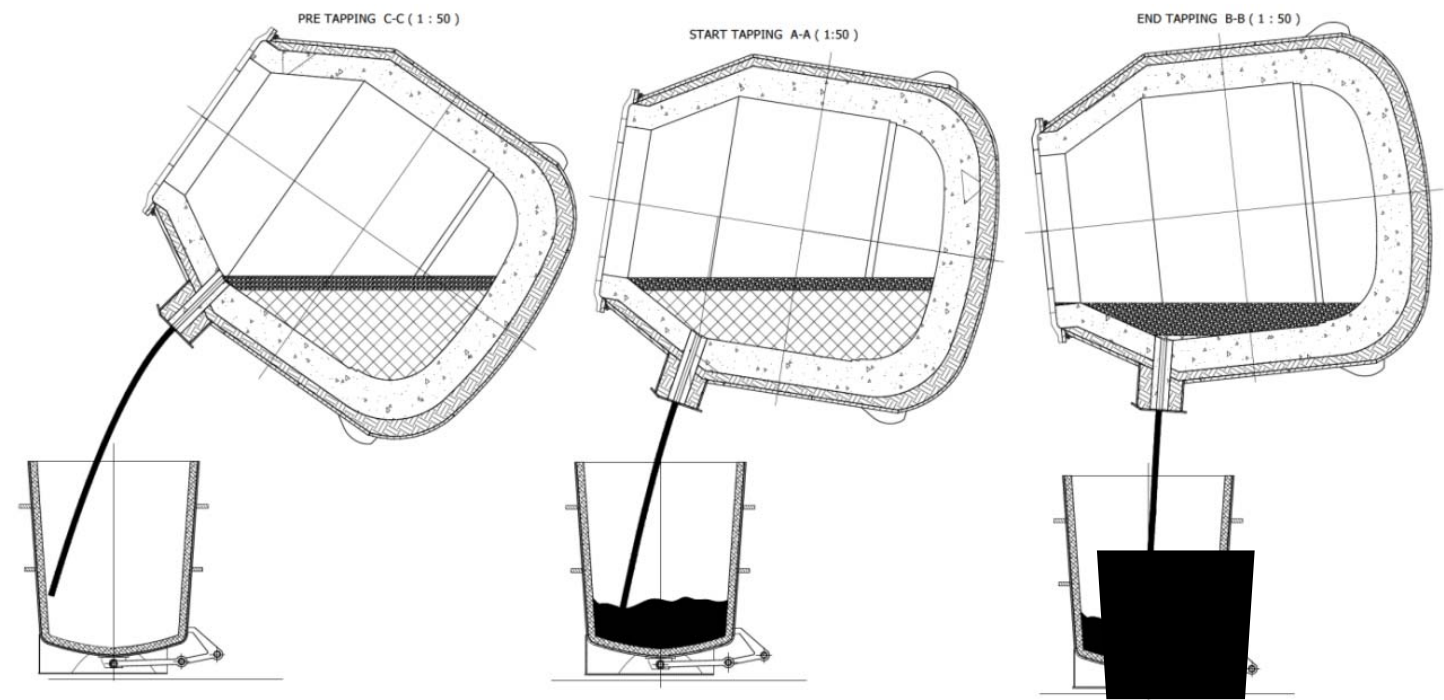

Figure 3. Investigation of tapping of liquid steel.

\subsection{Tilting Torque}

A key issue in the revamping application is the calculation of the tilting torques of the converter (Figure 4). In particular the converter with new lining- and worn line condition has to be considered in detail due to following reasons:

- The tilting torques should not be larger than the allowable limit of the existing tilting drive

- The tilting torques should be positive in any condition in for safety reason in order to guarantee that the converter has always a self-uprighting tendency.

* Technical contribution to the $45^{\text {th }}$ Steelmaking Seminar, May $25^{\text {th }}-28^{\text {th }}, 2014$, Porto Alegre, RS, Brazil. 

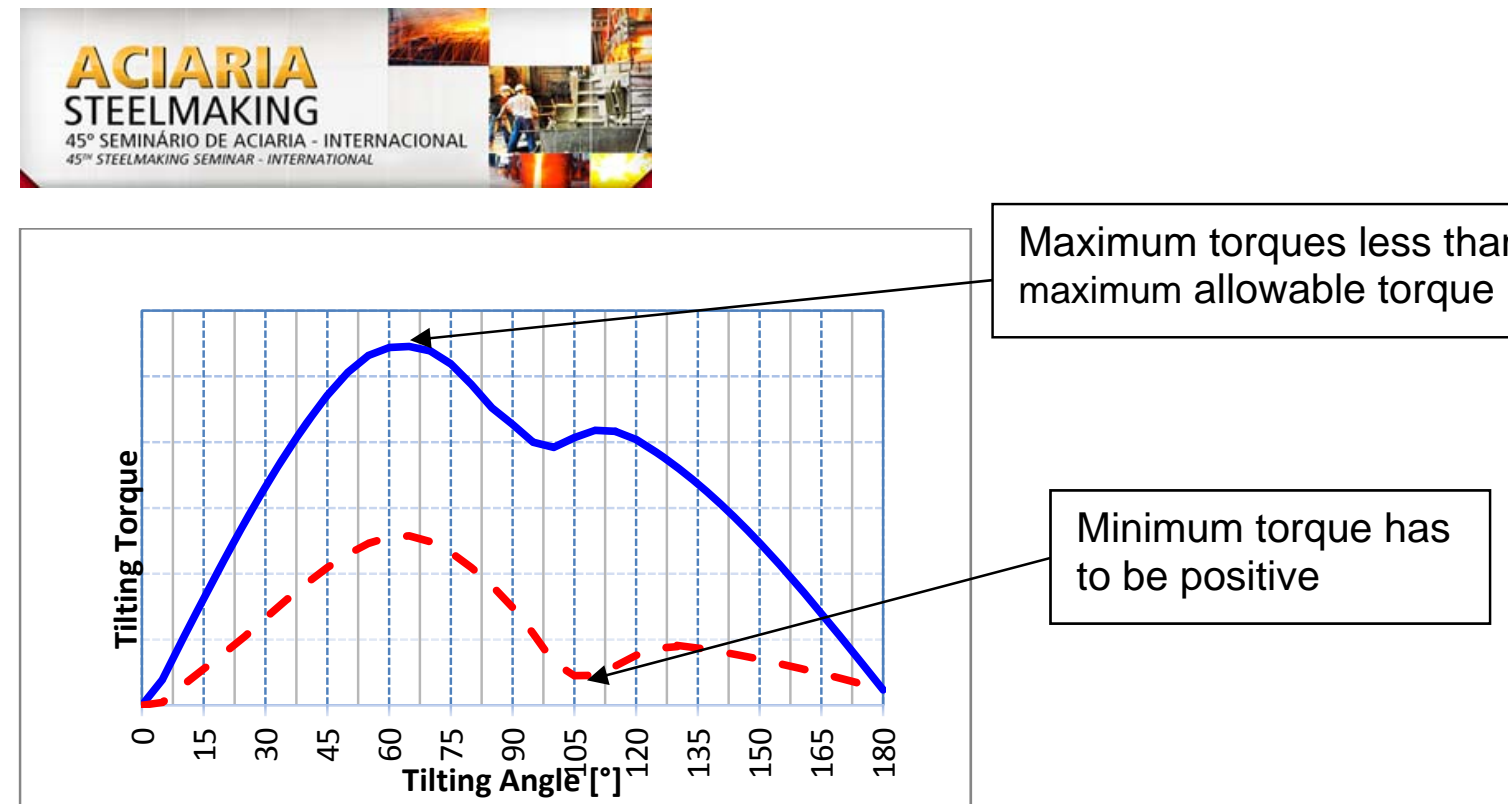

Figure 4. Tilting torques of the converter under new lining (solid line) and worn lining condition (dashed line).

In this specific application it was necessary to adopt the design of the new converter to fulfill the above mentioned criteria. So, additional measures had to be considered in order to avoid an overloading of the existing tilting drive. In order to fulfill this request flowing design optimization has been applied:

- Increase the thickness of the top cone

- Eccentric trunnion ring box relative to the tilting axes

- Increase the weight of the slag shields on top

- Add counter weights on the top cone (Figure 13).

\section{VESSEL SHELL}

The vessel shell is basically following the existing design consisting of:

- Top cone with flat lipring flange and stepped lipring segments

- Barrel section

- Big knuckle section

- Dished end.

The material of the vessel shell is chosen properly in order to have guaranteed strengths at elevated temperature as well as resistance against creep. However, the ultimate strength should be moderate in order to have a ductile material behavior and avoid brittle behavior of the steel e.g. in case of damages, burn through, cracks etc. In this particular case the vessel shell is made of $\mathrm{P} 355 \mathrm{GH}$ and the top cone of 16Mo3. These materials are perfect for such an application a still have acceptable weld ability [1-3].

The thicknesses of the plates have been chosen accordingly. However, in certain areas an increased thickness was selected.

\section{SUSPENSION SYSTEMS}

Very important for a smooth production during the life time of the vessel shell is the suspension system.

The targets for the suspension system are:

1. Keep the vessel shell in position all the time

2. Withstand all possible conditions which can happen

3. Be maintenance free.

* Technical contribution to the $45^{\text {th }}$ Steelmaking Seminar, May $25^{\text {th }}-28^{\text {th }}, 2014$, Porto Alegre, RS, Brazil. 
Ad 1: The suspension system is able to carry the load can be fulfilled and verified by calculations like finite element methods, etc.

Ad 2: To withstand all conditions is mostly evident due to the heavy design of the elements carrying the load of the converter.

Ad 3: Is most challenging, because is in some cases contradictable to the other two. However, Danieli developed and patented a new suspension system for this huge converter which can be subdivided into vertical suspension elements and horizontal suspension elements. This is characteristic for all the modern converter suspension systems available on the market for a certain size (>50 t). So, the suspension elements should be separated according to their loadings.

Most of the time the converter is in upright position, so the vertical elements are usually those which are loaded more or less continuously. However, the most critical element are those which are carrying the load in horizontal position. The time of exposure of the loading is much less but the load is much higher due to the fact that there are usually less elements for this type in contact which are consequently more loaded to fatigue.

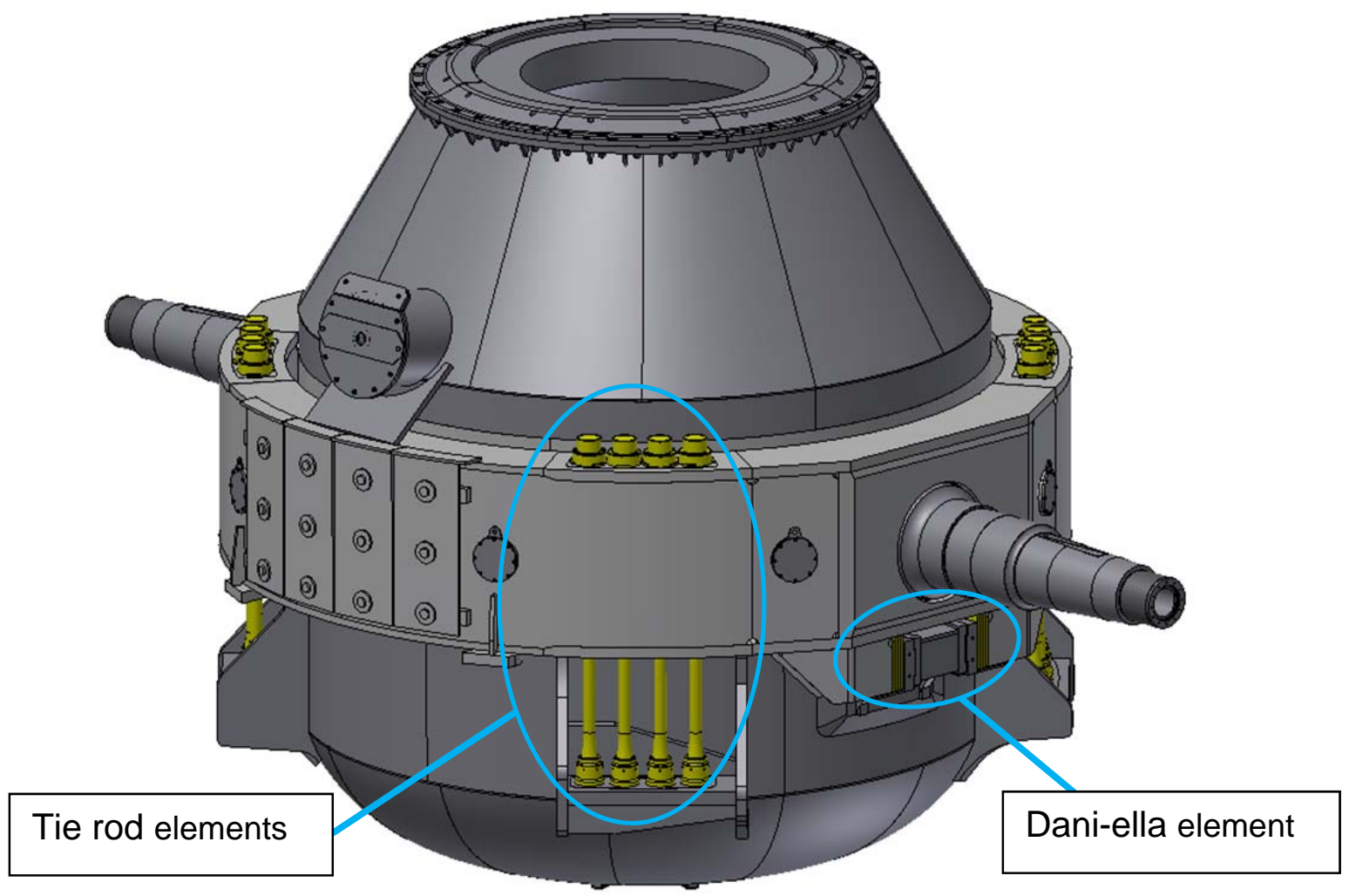

Figure 5. Arrangement of the Tie-rod suspension system in combination with the Dani-ella Element.

For AMP the converter suspension system is composed by:

- 4 Vertical tie rod elements each consisting of 4 tie-rods and

- 2 horizontal lamella type elements (Dani-ella elements) underneath the trunnion ring pins and

- 1 horizontal stabilizer on charging side.

In Figure 5 the arrangement of the suspension system is shown.

* Technical contribution to the $45^{\text {th }}$ Steelmaking Seminar, May $25^{\text {th }}-28^{\text {th }}, 2014$, Porto Alegre, RS, Brazil. 


\subsection{The Tie-Rod Suspension Elements for the Vertical Load}

The tie rods are fixed by bolt-nut connections on the upper end to the top flange of the trunnion ring and on the lower end to the bracket welded to the vessel shell. Any misalignment during installation is compensated by spherical washers (Figure 6).

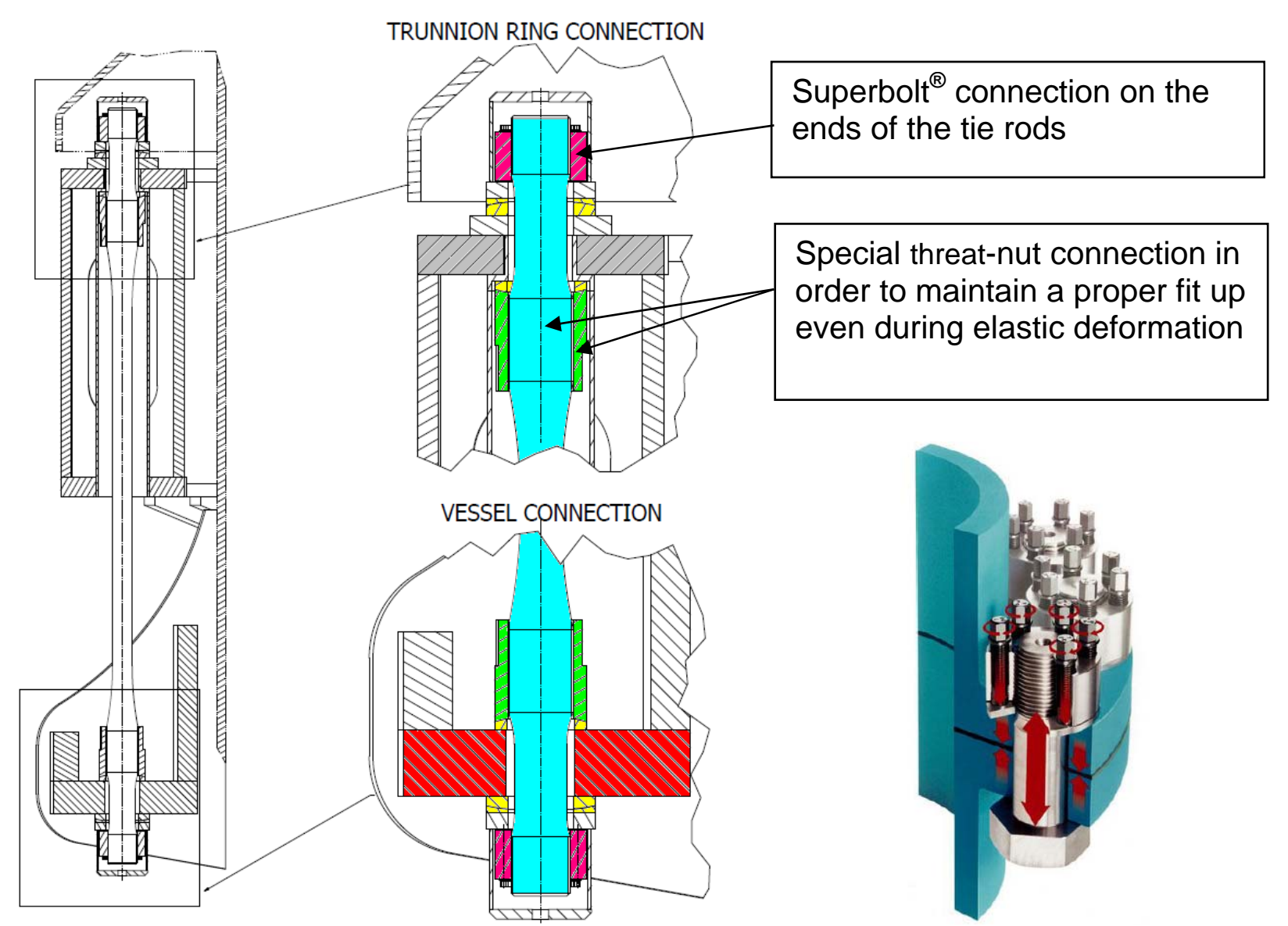

Figure 6. Details of the tie-rod suspension system and typical for super-bolt ${ }^{\circledR}$ connection.

Due to the arrangement of the tie rods there is elasticity of the suspension system in the radial direction of the converter and high stiffness in the circumferential direction of the converter. This supports the natural behavior of the converter. So, the thermal expansion of the vessel shell due to high temperature and long term deformation is compensated by elastic deformation of the tie rods. In the circumferential direction the suspension system should be stiff in order to carry the load together with the horizontal elements when the converter is in tapping-, charging- or temperature sampling position.

On the outer end of the tie rods the fixation is realized by applying super-nuts ${ }^{\circledR}$. This guarantees any easy and exact fixation of the tie rods. On the inner side a special nut threat connection is chosen. This guarantees a moderate stress level when additional bending occurs due to deformation of the vessel shell. Figure 7 shows the preassembly of the connection elements to the tie rods in the workshop.

* Technical contribution to the $45^{\text {th }}$ Steelmaking Seminar, May $25^{\text {th }}-28^{\text {th }}, 2014$, Porto Alegre, RS, Brazil. 

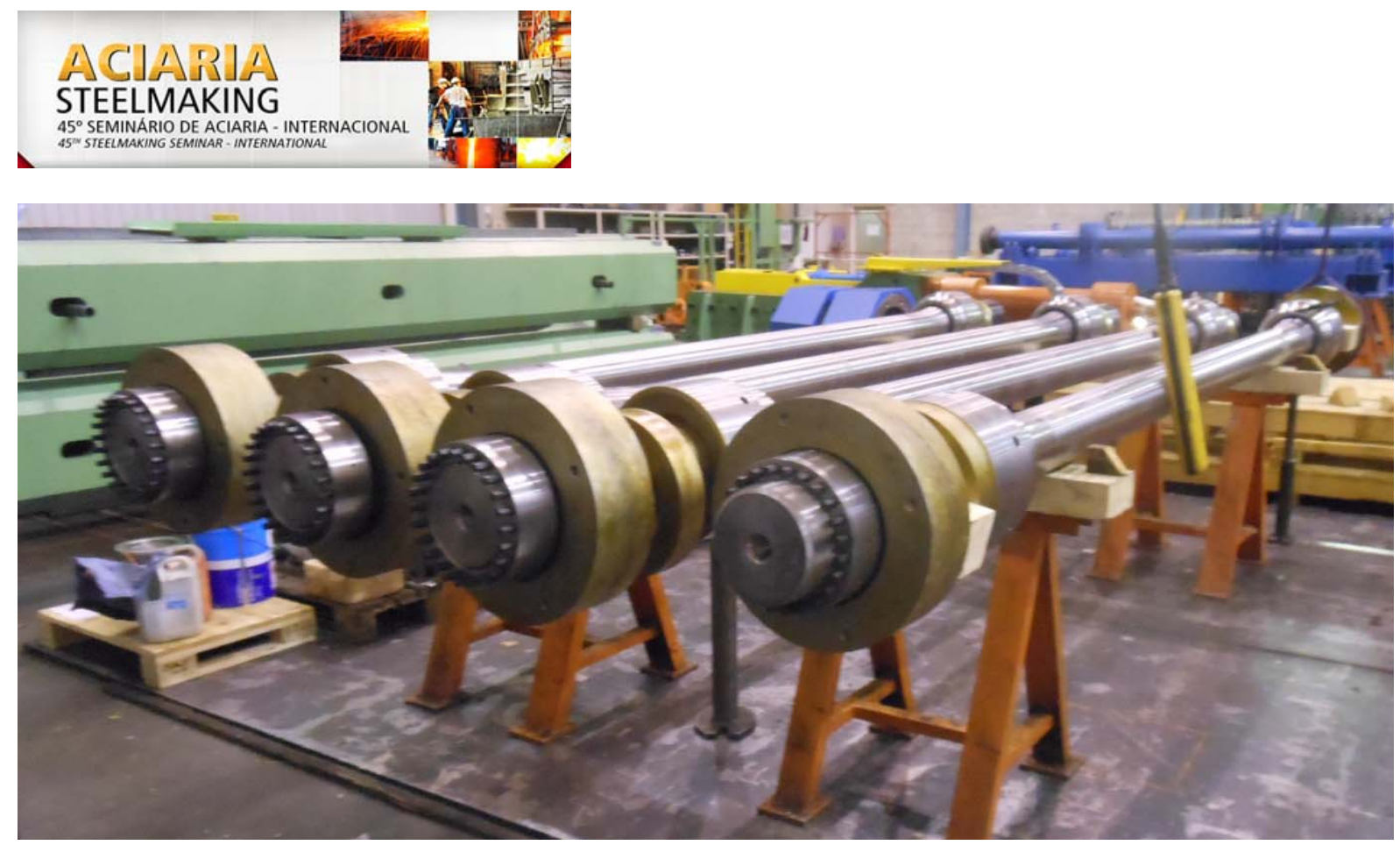

Figure 7. Pre-assembly of tie rods in the workshop.

\subsection{The Dani-Ella Suspension Element for the Horizontal Load}

The Dani-ella element has been developed in order to serve the support of the converter when it is tilted in $+/-90^{\circ}$ position. The target of this element was to be as simple as possible and easy to repair in case of an emergency.

Any element on the suspension has to withstand special conditions under operation condition of a BOF. In particular the horizontal element has to introduce the horizontal load from vessel shell to the trunnion ring. All other possible loads should be uncoupled. So, the thermal expansion or long term deformation of the vessel shell should be unhindered in order to avoid additional reaction forces. With this design, shown in Figure 8 the thermal expansion of the bracket welded to the vessel shell has to be considered only. Particularly this task is taken care by elastic elements which compensate the thermal expansion effect by elastic deformation within certain limits. For these elastic elements lamella plates are chosen. For this special design and arrangement a patent was application was registered as well.
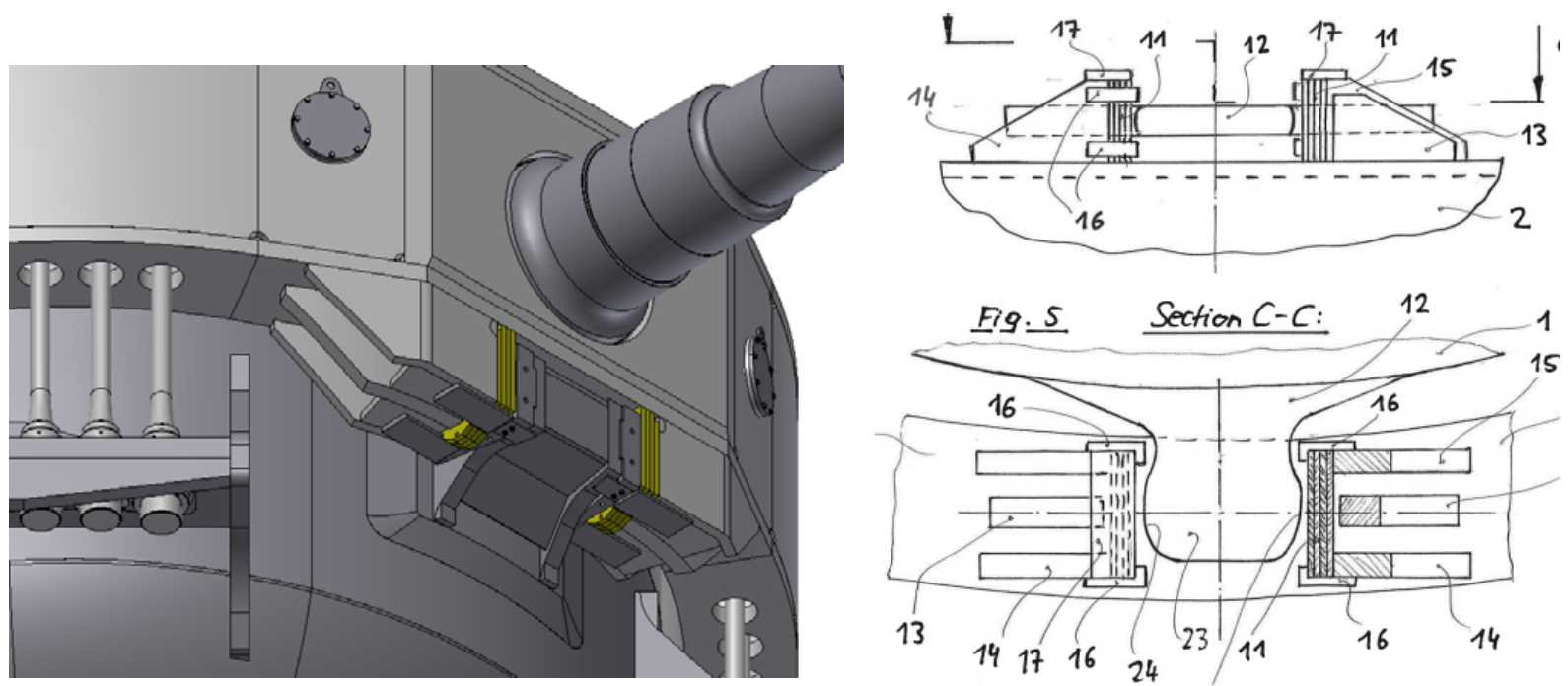

Figure 8. Dani-ella horizontal suspension element and sketch issued in the patent.

* Technical contribution to the $45^{\text {th }}$ Steelmaking Seminar, May $25^{\text {th }}-28^{\text {th }}, 2014$, Porto Alegre, RS, Brazil. 
The principle is shown in the sketches below (Figure 9):

There is a certain clearance between the lamella plates and the horizontal elements welded to the trunnion ring. When the vessel shell gets elevated temperatures the trunnion ring is always cooler and the bracket on the vessel shell will grow and reducing the remaining clearance to the bracket on the trunnion ring.

In case the converter has reached its maximum temperature the clearance is closed and the horizontal forces can be directly introduced from the vessel shell via the lamella plates into the trunnion ring bracket.

Following advantages come along with this design:

- Simple and very robust design

- No special parts involved. So, any repair can be done by maintenance staff only. Not special tool or equipment involved.

- Lamella plates are just inserted between bracket welded to vessel shell and trunnion ring and are just kept in position be welded on holder plates. So, these plates can easily be changed in case of an emergency of in case the clearance of the element is of interest to be changed.

- Relative movement caused by thermal expansion or long term deformation are basically developed slowly and will take place when the converter is in blowing position (most of the time the converter is in this position). So, the wear due to this relative movement will be very small because in blowing position this elements is unloaded.

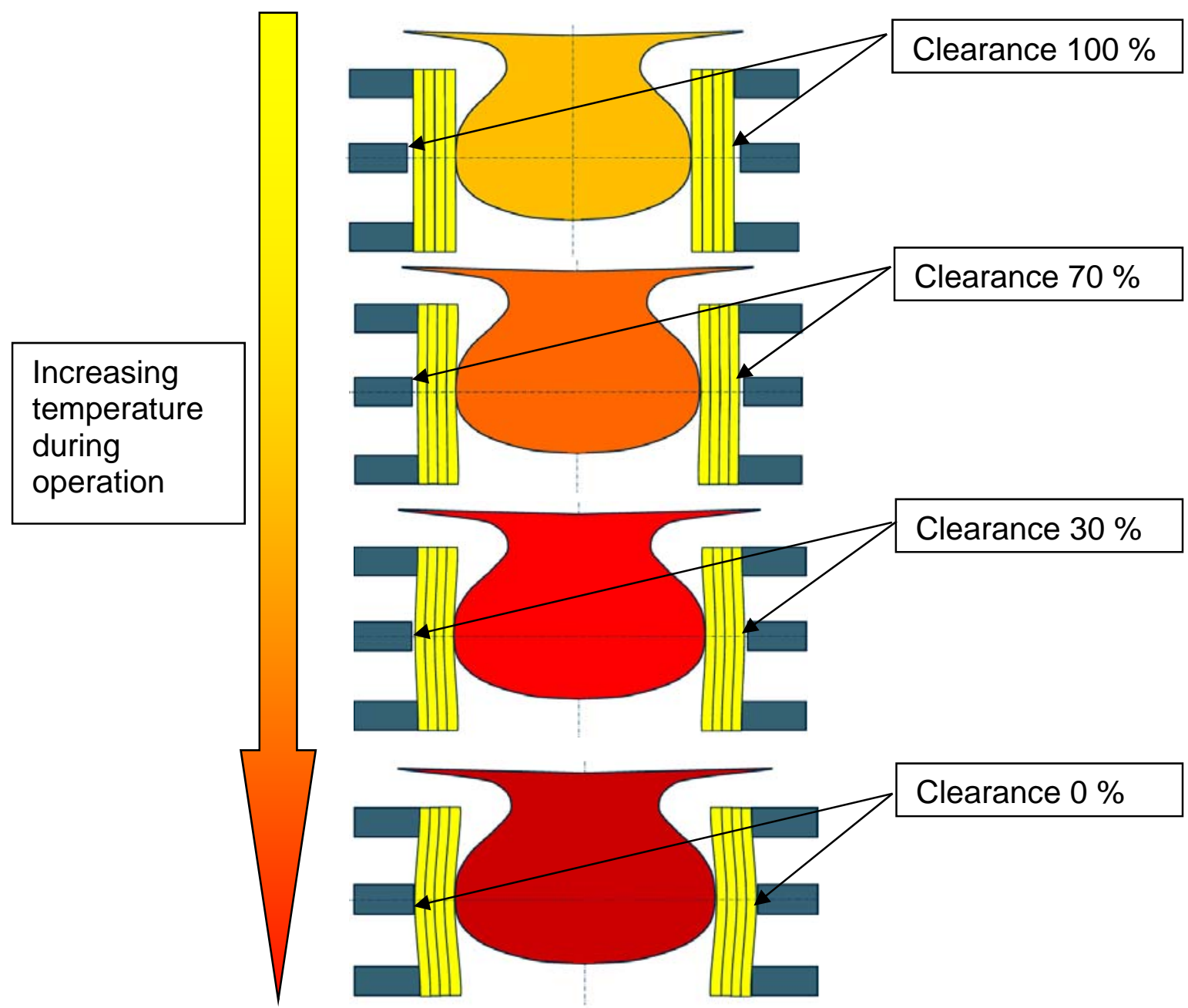

Figure 9. Principle of the Dani-ella suspension system.

${ }^{*}$ Technical contribution to the $45^{\text {th }}$ Steelmaking Seminar, May $25^{\text {th }}-28^{\text {th }}, 2014$, Porto Alegre, RS, Brazil. 


\section{TRUNNION RING}

Due to the fact that the existing tilting drives have to be re-used the trunnion ring is a state-of the art design combined with pins following the existing design in order to match with the existing tilting drives. Due to the huge dimensions there are 2 large tilting drives with 6 motors each arranged. Consequently the trunnion ring has 2 long pins.

The trunnion ring has a total length of $19920 \mathrm{~mm}$, an outer diameter of $11420 \mathrm{~mm}$, a box height of $2600 \mathrm{~mm}$ and a total weight of approx. $230000 \mathrm{~kg}$.

The bearing distance is $13120 \mathrm{~mm}$ and the bearing diameter is $1180 \mathrm{~mm}$. In order to help in the compensation of the tilting torque the pins have an offset to the center of the box section of $150 \mathrm{~mm}$ (Figure 10).

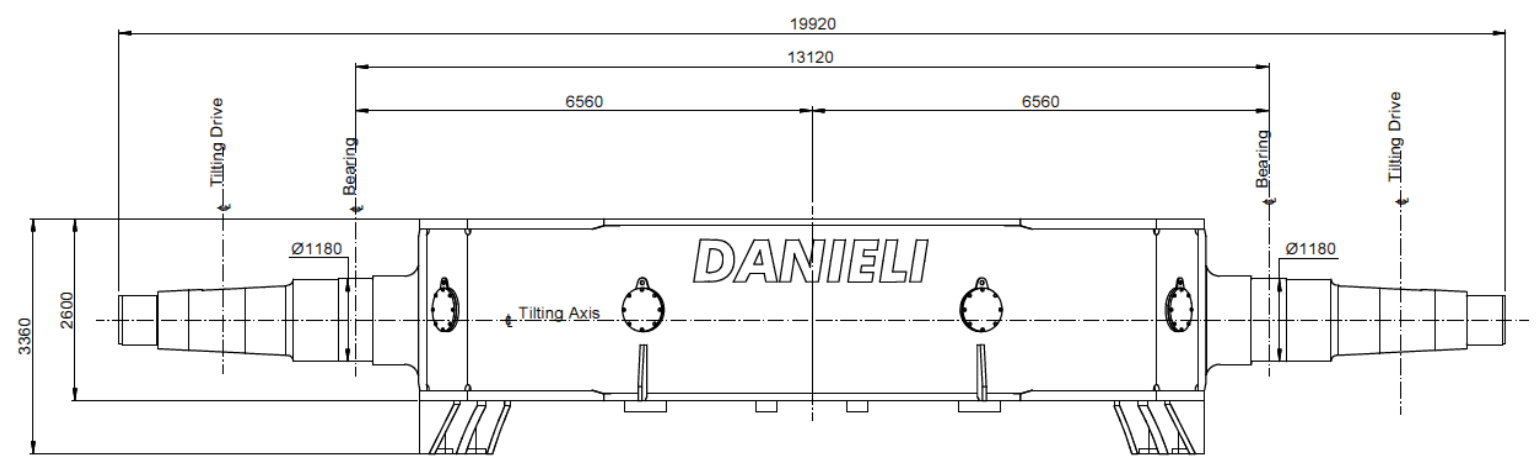

Figure 10. Main dimensions of trunnion ring.

\section{MANUFACTURING}

The manufacturing of the main parts (vessel shell, trunnion ring, slag shields, pedestals) have been applied within Danieli pressure vessel division at Danieli Thailand.

This workshop is certified according to ISO 9001:208, ISO 14000, ISO 18000 and particularly the boiler and pressure vessel division is certified according to ASME boiler and pressure vessel code (U2 and $U$ for production of pressure vessels as well on site, PP for production of pressure piping and $\mathrm{S}$ for power boilers), certified by the national board (NB) to manufacture boiler and pressure vessels and apply NB-mark and R-symbol. So, it can be guaranteed that all requirements are fulfilled and under full control of Danieli.

The most critical manufacturing issue is however, the trunnion ring. Due to the huge dimension of this part special procedures have to be applied. As state of the art trunnion rings are usually fabricated in four pieces (2 pin sections and 2 intermediate or banana sections) and then welded together. Usually this joint welded has to be applied on site because of dimensional and weight limitations during transport. The pin section is usually made in a way that the pre-machined pin is welded to the box type section, heat treated and then finally machined together with the box type carpentry. However, this procedure could not been applied for this project due to limitation in machining of this section.

So, Danieli developed a special procedure with following main steps:

- Welding of all 4 box type sections independently;

- Fit up of these 4 sections on a layout and find an optimum alignment;

- Tack welding of these 4 sections;

* Technical contribution to the $45^{\text {th }}$ Steelmaking Seminar, May $25^{\text {th }}-28^{\text {th }}, 2014$, Porto Alegre, RS, Brazil. 


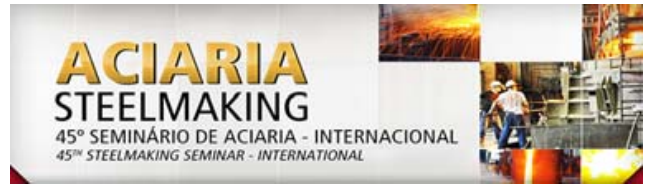

- Apply post weld heat treatment;

- Installation and fully welding of the final machined pins into the box type carpentry (Figure 11);

- Apply local post weld heat treatment of the pin weldings;

- Alignment of full trunnion ring on layout in the workshop (Figure 12);

- Transport of these 4 sections to site;

- Site assembly and alignment of these 4 sections in the same way as in workshop;

- Apply site welding of the joints and local post weld heat treatment of these site welding.

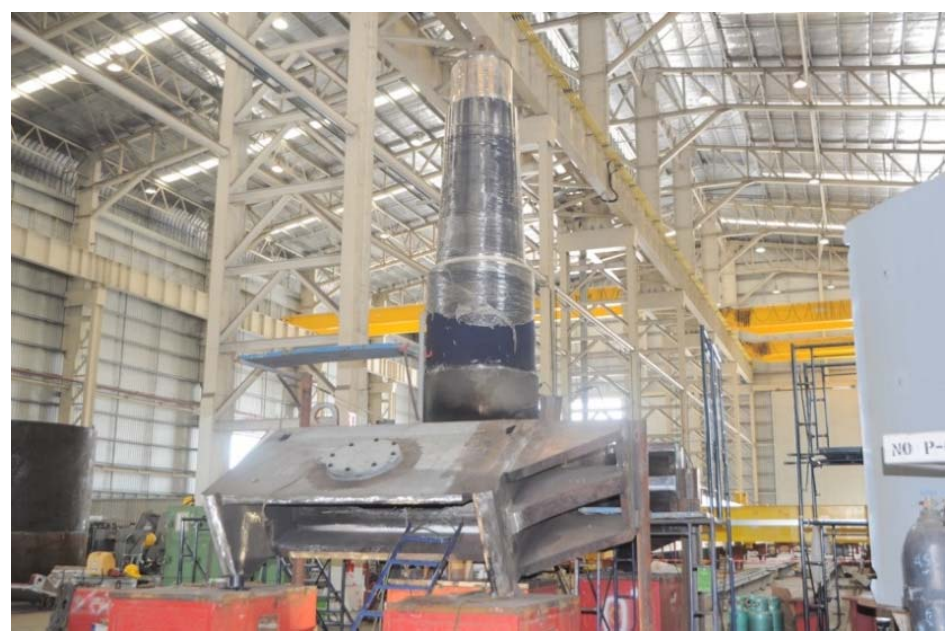

Figure 11. Pin section with welded in pin in final machined condition.

This comes along with certain advantages like, minimizing of delivery time by incorporating upcoming projects already in the schedule of the workshop. Optimization of manufacturing in terms of engineering adopted to the capabilities of the workshop.

This gains in minimizing the number of welding seams, minimize welding sizes in order to reduce residual stress. All manufacturing steps can be done in-house like pressing of bottom dish end or knuckle sections, stress reliving of complete trunnion ring, local stress relieving, developing of special welding procedures (WPS, WPQR and PQR) together with the Danieli welding engineers and so on. All NDT and NDE is applied in-house with qualified personnel (Level II and Level III). The quality control plan (QCP) is issued by the engineering department and directly implemented in the manufacturing process.

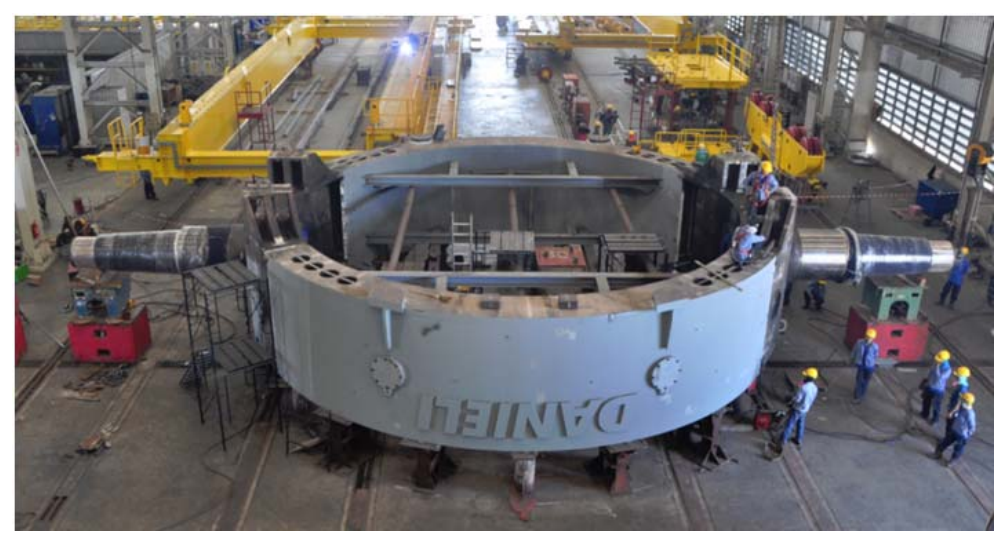

Figure 12. Final fit-up of trunnion ring in workshop before shipment.

* Technical contribution to the $45^{\text {th }}$ Steelmaking Seminar, May $25^{\text {th }}-28^{\text {th }}, 2014$, Porto Alegre, RS, Brazil. 


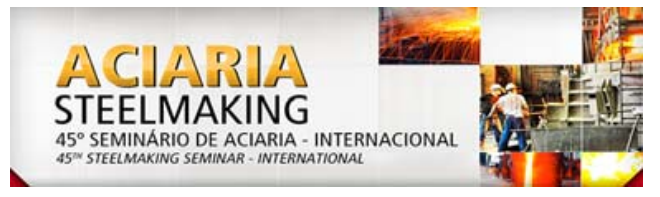

Keeping in mind, that manufacturing as well as pre-assembly and erection on site is done by Danieli, the preparation for site can be optimized in order to increase the quality and gain erection time.

The complete supply chain is in one hand and under full quality control of the Danieli quality control system.

With this workshop it is possible to provide additional services like keeping material or spare parts on stock for emergency cases like burn through or other unforeseeable events in order to assist steel producer in such situations.

The vessel shell has been manufactured in 7 parts (2 bottom-, 3 barrel- and 2 top cone-parts) with all suspension elements already welded on. The large bottom part with its main dimensions of $\mathrm{L}=11300 \mathrm{~mm} \times \mathrm{B}=5750 \mathrm{~mm} \times \mathrm{H}=4550 \mathrm{~mm}$ and $\mathrm{a}$ transport weight of $97 \mathrm{t}$ is shown in Figure 13.
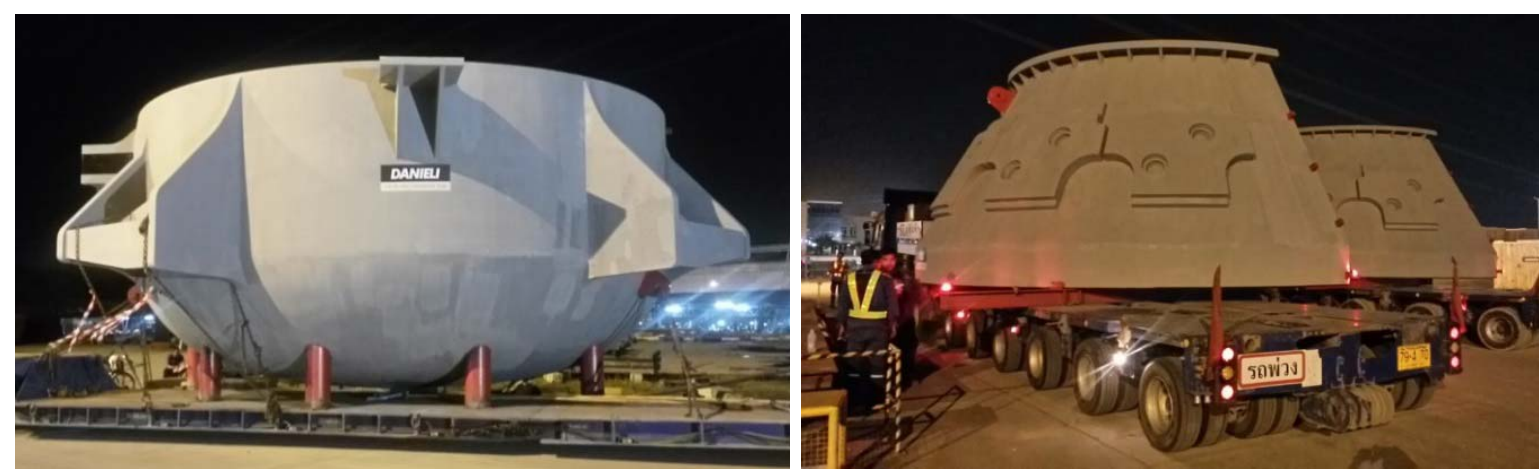

Figure 13. Transport of bottom part and top cone part to the port in Thailand.

\section{ERECTION}

The pre-assembly and final welding of the vessel shell will start approx. by mid of January 2014 and for the trunnion approx. mid of February 2014. The erection itself is planned to be applied in April 2014 with hot commissioning beginning of May 2014.

\section{REFERENCES}

1 Di Napoli D, De Oliveira JG, Staudinger G, Müller J. Design aspects of the ideal LD steelmaking converter. In: AISE Annual Convention and Exposition; 2003, Pittsburgh, USA. Warrendale: AIST; 2003.

2 Guzela JG, De Oliveira JG, Staudinger G, Müller J. The ultimate LD steelmaking converter -the synthesis of 50 years of development. In: $4^{\text {th }}$ European Oxygen Steelmaking Conference; 2003, Graz, Austria. Leoben: ASMET - Austrian Society for Metallurgy and Materials; 2003.

3 Staudinger G, Reiter T. Estimation of the allowable loadcycles of a machine-part until fracture. Technology, Law and Insurance. 1998;3:197-201.

* Technical contribution to the $45^{\text {th }}$ Steelmaking Seminar, May $25^{\text {th }}-28^{\text {th }}, 2014$, Porto Alegre, RS, Brazil. 